\title{
A randomized phase II study of S-1 monotherapy versus cisplatin with vinorelbine for completely resected stage II/IIIA non-small cell lung cancer: rationale and study protocol design for the LOGIK1702 study
}

Tomoshi Tsuchiya ${ }^{* *}$ (D), Keitaro Matsumoto ${ }^{1}$, Takuro Miyazaki ${ }^{1}$, Ryoichiro Doi ${ }^{1}$, Shoji Tokunaga ${ }^{2}$, Hiroyuki Yamaguchi ${ }^{3}$, Koichi Tomoshige ${ }^{1}$, Hironosuke Watanabe ${ }^{1}$, Takeshi Nagayasu ${ }^{1}$ and Kenji Sugio ${ }^{4}$

\begin{abstract}
Background: The current standard postoperative treatment for stage II-IIIA non-small cell lung cancer (NSCLC) is a regimen of platinum doublet adjuvant chemotherapy. These regimens, which are the same as for solid NSCLC tumors, often cause severe adverse reactions in the treated patients. Therefore, an effective treatment regimen with fewer side effects is needed.

Methods/design: The purpose of this study is to evaluate the effectiveness and safety of S-1 monotherapy (80 mg/ $\mathrm{m}^{2}$ orally administrated twice daily, at day $1-14,16$ cycles) and cisplatin with vinorelbine combination therapy (cisplatin $80 \mathrm{mg} / \mathrm{m}^{2}$ at day 1,vinorelbine $25 \mathrm{mg} / \mathrm{m}^{2}$ at day $1,8,4$ cycles) in patients with II/IIIA stage non-small-cell lung cancer who underwent a total resection. In addition, we will also evaluate the level of treatment side effects by assessing quality of life (QOL), work productivity and activity performance. The primary endpoint is a 2-year relapse free survival (RFS) and the second primary endpoints are 2-year overall survival (OS), rate of treatment completion, safety, work productivity and activity, and quality of adjusted life years (QALY). At the same time, we aim to obtain precise information required to perform future phase 3 randomized controlled trials. The study is designed to estimate the primary endpoint with accuracy determined as the width of its $95 \%$ confidence interval to be less than 20\%. Recruitment started in May 2017 and is ongoing.
\end{abstract}

Discussion: This study has been conceived to establish a superior regimen for completely resected NSCLC based on efficacy, safety and QOL.

Trial registration: Registry number: UMIN000027435. Registered May 22, 2017.

Keywords: Adjuvant chemotherapy, S-1, Cisplatin, Feasibility study, Quality of life non-small cell lung cancer

\footnotetext{
* Correspondence: tomoshi@nagasaki-u.ac.jp

'Department of Surgical Oncology, Nagasaki University Graduate School of Biomedical Sciences, 1-7-1 Sakamoto, Nagasaki City 852-8501, Japan

Full list of author information is available at the end of the article
}

(c) The Author(s). 2021 Open Access This article is licensed under a Creative Commons Attribution 4.0 International License, which permits use, sharing, adaptation, distribution and reproduction in any medium or format, as long as you give appropriate credit to the original author(s) and the source, provide a link to the Creative Commons licence, and indicate if changes were made. The images or other third party material in this article are included in the article's Creative Commons licence, unless indicated otherwise in a credit line to the material. If material is not included in the article's Creative Commons licence and your intended use is not permitted by statutory regulation or exceeds the permitted use, you will need to obtain permission directly from the copyright holder. To view a copy of this licence, visit http://creativecommons.org/licenses/by/4.0/ The Creative Commons Public Domain Dedication waiver (http://creativecommons.org/publicdomain/zero/1.0/) applies to the data made available in this article, unless otherwise stated in a credit line to the data. 


\section{Background}

Lung cancer remains the leading cause of cancer-related deaths worldwide. In order to prevent lung cancer recurrence, adjuvant chemotherapy in post-operative patients with stage IB-IIIA non-small cell lung cancer (NSCLC) has been established as the standard treatment [1-3]. The standard regimen for adjuvant chemotherapy is intravenous administration of a platinum doublet [3]. However, the representative regimen of cisplatin (CDDP) with vinorelbine (VNR) causes grade three or four adverse reactions including severe leukopenia, neutropenia, anemia, aspartate aminotransferase (AST) elevation, nausea, vomiting, constipation, asthenia, injection site reaction, and prolonged peripheral neuropathy in more than $70 \%$ of patients. Renal dysfunction often occurs and sometimes remains lifelong. Given the severe adverse reactions to this standard adjuvant chemotherapy and the fact that there are few remnant malignant cells in the postoperative patients, milder treatment options have been considered.

A recent study of the 5-year survival in a randomized phase III study of cisplatin with pemetrexed versus cisplatin with vinorelbine for completely resected stage IIIIIA non-squamous NSCLC (the JIPANG study) was reported (ASCO 2019 8501). The JIPANG study failed to show the superiority of pemetrexed plus cisplatin over vinorelbine plus cisplatin and the cost of pemetrexed is high. However, the regimen will be considered as an option for adjuvant chemotherapy for stage II-IIIA nonsquamous NSCLC since the effect is comparable and the patients treated with cisplatin and pemetrexed had a higher completion rate with low adverse reactions compared to the patients treated with cisplatin and vinorelbine. Another recent approach is the use of immune checkpoint inhibitors (ICI) for postoperative patients. Several clinical trials of ICI with/without chemotherapy are currently underway in adjuvant setting [4]. The trials are expected to be completed during 2024 or later. Thus the efficacy and the adverse reactions of ICI in adjuvant therapy remain unclear.

S-1 might be another candidate for mild adjuvant chemotherapy for NSCLC. The oral fluoropyrimidine derivative which consists of tegafur and two modulators, 5-chloro-2,4-dihydroxypyridine (CDHP) and potassium oxonate (Oxo), enhances 5-FU efficacy by inhibiting degradation of 5-FU and reduces the GI toxicity caused by 5-FU [5]. The significant effects with low adverse reactions of S-1 monotherapy in an adjuvant treatment have been proven in randomized phase III trials in digestive cancers including gastric, pancreatic and colon adenocarcinomas [6-8]. Accordingly, S-1 based adjuvant chemotherapy has been used as an option of standard treatment in intestinal cancers. Further, S-1 also has efficacy against squamous cell carcinomas including head and neck, oral, esophagus and thymus [9-11], suggesting $\mathrm{S}-1$ is effective on both squamous carcinomas and adenocarcinomas.

Feasibility studies of S-1 based adjuvant chemotherapy for patients with stage IB to IIIA NSCLC have also been conducted $[12,13]$. The results indicate that the completion rates of planned one-year treatment courses were comparable to platinum doublet $(50-72 \%)$ and the grade 3 adverse reactions were very low (4-20\%) with no grade 4 adverse reactions. The grade $3 / 4$ neutropenia was extremely low (0-6.7\%), compared to the meta-analysis of cisplatin with vinorelbine adjuvant chemotherapy of $80 \%$ [14]. The 5-year overall and relapse free survival rates of the S-1 treated postoperative patients with stage IB-IIIA NSCLC were 72.5 and $67.5 \%$, which are obviously better than those of previously reported studies including platinum doublet based adjuvant chemotherapies [12]. The randomized phase II study of adjuvant chemotherapy with S-1 and cisplatin with S-1 revealed that the survival rates of both groups overlap in patients with completely resected stage II-IIIA NSCLC [15], indicating that S-1 monotherapy has the potential for replacing the standard regimen of platinum doublet by virtue of its efficacy and safety.

The low incidence of adverse reaction directly correlates with the quality of life of the treated patients. Because of mild adverse reactions, S-1 can be administrated for outpatients without hospitalization and treated patients can continue daily life and working, which will maintain the social productivity of the treated individuals. The evaluation of quality of life (QOL) and work productivity of postoperative patients shows the advantage of S-1 chemotherapy versus standard platinum doublet adjuvant chemotherapy. Taken together, these findings have enabled us to design the current phase II study to confirm the beneficial effects of S-1 in adjuvant chemotherapy. In this article, we describe the protocol (version 2; January 14, 2020) for this study. The results of this study are expected to provide basic information for raising the precision of performance for a randomized phase III study.

\section{Methods/design \\ Study design and treatment}

The present study is a multicenter, phase II, randomized, open-labelled, parallel-group comparison study of the efficacy and safety of S-1 compared with cisplatin plus vinorelbine for adjuvant therapy in patients with NSCL C. The study design is summarized in Fig. 1. Patients are randomized in a 1:1 ratio to the experimental arm (1 year of S-1 administration) or control arm (four cycles of cisplatin with vinorelbine administration), stratified according to sex (female vs. male), age ( $<70$ years vs. 70 years), pathologic stage (II vs. IIIA) and pathology 


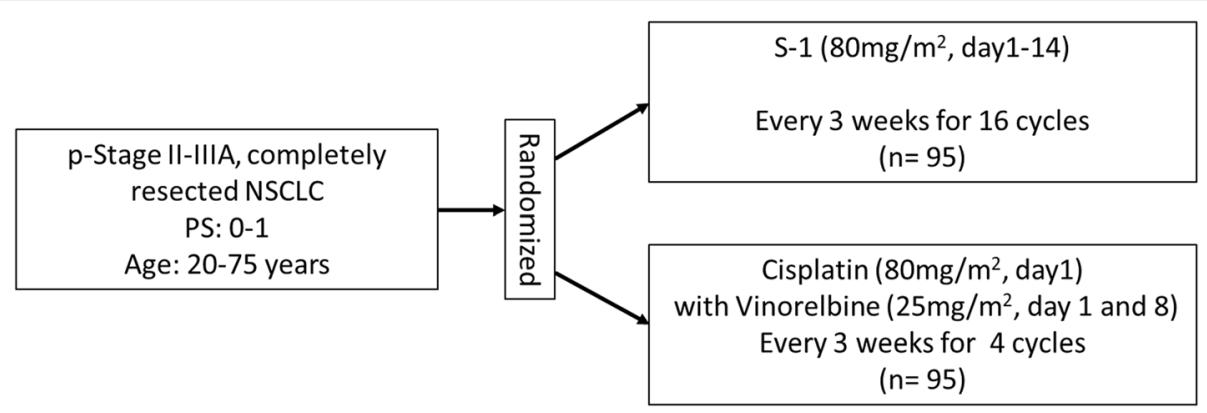

Fig. 1 Study Design of LOGIK1702 Study, A Randomized Phase II Study of S-1 and Cisplatin with Vinorelbine for Completely Resected Stage II/IIIA NSCLC

(squamous cell carcinoma vs. non- squamous cell carcinoma). The primary endpoint is 2-year relapse-free survival (RFS). The secondary endpoints are 2-year overall survival (OS), rate of treatment completion, safety, work productivity and activity, and quality of adjusted life years (QALY). QALY is calculated by the time points of QOL converted from the questionnaire method using Euro QoL 5 dimensions (EQ-5D-5L) [16] and conversion chart. The EQ-5D-5L and work productivity and activity impairment (WPAI) are surveyed by questionnaires for one and a half years from the start of adjuvant chemotherapy (Fig. 2).

The study is being conducted at 30 institutions in the Lung Cancer Group in Kyusyu (LOGIK) in Japan. The study is registered with the University Hospital Medical Information Network Clinical Trials Registry (www. umin.ac.jp/ctr/) under registration number UMIN00002 7435. We conduct the study in accordance with the principles of the Declaration of Helsinki. The central ethics committee approved the study.

All eligible patients will be selected and approached on the basis of information derived from the electronic health records of these 30 institutions (academic hospitals) according to the inclusion and exclusion criteria. Participants will be provided with an explanation about the study by their treating physicians, and they will be asked to voluntarily sign an informed consent before participation. If the patient's consent is obtained, a clinical trial physician will perform the observation/examination based on the description in Fig. 2a and b.

\section{Eligibility criteria}

The main patient inclusion and exclusion criteria are detailed in Table 1.

\section{Treatment}

Arm A (S-1 monotherapy) is an adjuvant therapy of S-1 for 16 courses (1 year). S- $180 \mathrm{mg} / \mathrm{m}^{2}$ is orally administered twice daily (after breakfast and dinner) from after breakfast at day 1 to after dinner at day 14 (or from after dinner at day1 to after breakfast at day 15) as 21 days of 1 course.

Arm B (Cisplatin with vinorelbine combination therapy) is an adjuvant therapy of cisplatin with vinorelbine for 4 courses. Cisplatin $80 \mathrm{mg} / \mathrm{m}^{2}$ at day1 and vinorelbine $25 \mathrm{mg} / \mathrm{m}^{2}$ at day 1,8 are administered as 21 days of 1 course for 4 courses.

\section{Randomization}

After the acquisition of written informed consent and the completion of baseline measurements, the enrolled participants are registered and assigned treatment by the registration center. Participants will be randomly allocated at a ratio of 1:1 (S1 versus Cisplatin with vinorelbine). Randomization will be performed using the block randomization method with randomly varying block length utilizing SAS version 9.4 software (SAS Institute, Cary, NC, USA).

\section{Statistical design and sample size considerations}

This aim of this study is to estimate the 2 year relapsefree survival rate (RFS) for each study arm with sufficient clinical precision. The statistical comparison of the difference in RFS between the two arms is not a primary aim. We designed the sample size to estimate the 2year-RFS with the accuracy determined to be the width of the $95 \%$ confidence interval for the 2 year-RFS to be less than $20 \%$. The 2-year RFS was expected to be $65 \%$. Assuming an estimate at the $95 \%$ confidence interval for the 2 year-RFS with the Wilson's method, 84 patients are necessary for each arm. Estimating around 10\% drop outs, we set the total number of patients to be 190 . The above sample size was set to assure the statistical power to quantitatively compare the primary point between the arms. The primary goal of this study is to evaluate the clinical significance of the S1 monotherapy by integrating the observed data of the RFSs, QOL and adverse events of the two arms.

Relapse-free survival was defined as the time from the date of the start of treatment to the date of disease 


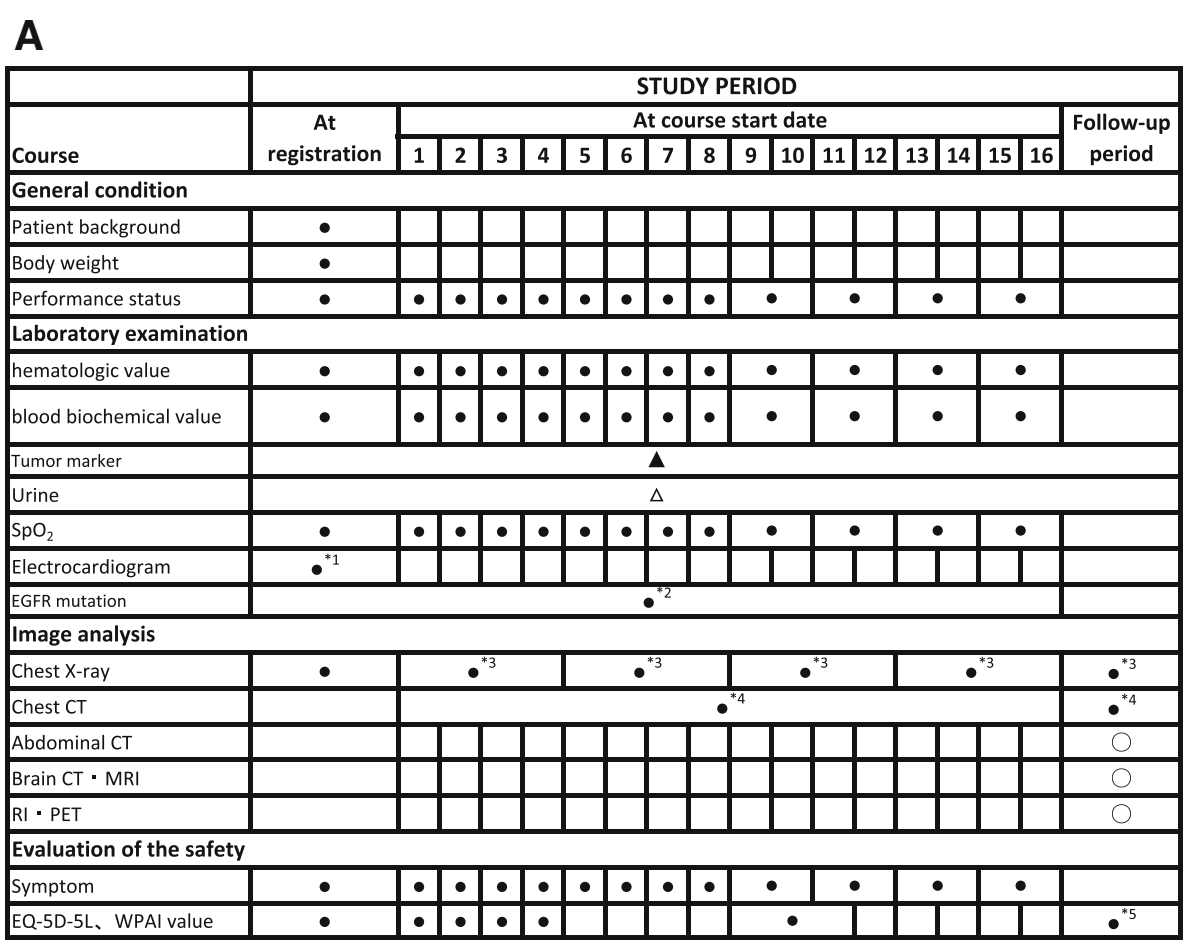

B

\begin{tabular}{|c|c|c|c|c|c|c|c|c|c|c|c|c|c|c|}
\hline & \multicolumn{14}{|c|}{ STUDY PERIOD } \\
\hline Course & \multirow{2}{*}{ At registration } & \multicolumn{3}{|c|}{1} & \multicolumn{3}{|c|}{2} & \multicolumn{3}{|c|}{3} & \multicolumn{3}{|c|}{4} & \multirow{2}{*}{$\begin{array}{l}\text { Follow-up } \\
\text { period }\end{array}$} \\
\hline Timepoint(Week) & & 1 & 2 & 3 & 4 & 5 & 6 & 7 & 8 & 9 & 10 & 11 & 12 & \\
\hline \multicolumn{15}{|l|}{ General condition } \\
\hline Patient background & - & & & & & & & . & & & & & & \\
\hline Body weight & - & 이 & & & - & & & - & & & - & & & \\
\hline Performance status & - & - & & & - & & & - & & & 0 & & & \\
\hline \multicolumn{15}{|l|}{ Laboratory examination } \\
\hline hematologic value & 으 & 이 & - & & 인 & el & & 이 & 이 & & - & 0 & & \\
\hline blood biochemical value & $\bullet$ & $\bullet$ & $\bullet$ & & - & 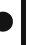 & & - & - & & 0 & - & & \\
\hline Tumor marker & \multicolumn{13}{|c|}{$\Delta$} & \\
\hline Urine & \multicolumn{13}{|c|}{$\triangle$} & \\
\hline $\mathrm{SpO}_{2}$ & - & \multirow{2}{*}{\multicolumn{3}{|c|}{0}} & \multicolumn{2}{|l|}{ 우 } & \multirow{2}{*}{\multicolumn{3}{|c|}{ 은 }} & \multicolumn{3}{|c|}{0} & & \\
\hline Electrocardiogram & $0^{* 1}$ & & & & & & & & & & & & & \\
\hline EGFR mutation & \multicolumn{13}{|c|}{$\mathbf{0}^{* 2}$} & \\
\hline \multicolumn{15}{|l|}{ Image analysis } \\
\hline Chest X-ray & 운 & \multicolumn{3}{|c|}{$0^{* 3}$} & \multicolumn{3}{|c|}{$\mathbf{Q}^{* 3}$} & \multicolumn{3}{|c|}{$\mathbf{0}^{* 3}$} & \multicolumn{3}{|c|}{$0^{* 3}$} & $\mathbf{0}^{* 3}$ \\
\hline Chest CT & & & & & & & & & & & & & & $0^{* 4}$ \\
\hline Abdominal CT & & & & & & & & & & & & & & $\mathrm{O}$ \\
\hline Brain CT·MRI & & & & & & & & & & & & & & 0 \\
\hline $\mathrm{RI} \cdot \mathrm{PET}$ & & & & & & & & & & & & & & 0 \\
\hline \multicolumn{15}{|l|}{ Evaluation of the safety } \\
\hline Symptom & 은 & - & - & & 인 & D & & - & - & & 이 & - & & \\
\hline EQ-5D-5L, WPAI value & • & $\bullet$ & & & • & & & 0 & & & $\bullet$ & & & $\mathbf{O}^{* 5}$ \\
\hline
\end{tabular}

Fig. 2 Treatment schedule and outcome measures of arm A (2A) and arm B (2B). $\bullet$; Measurements, $\boldsymbol{\Delta}$; Measurable facilities (Once a month), $\Delta$; optional. *1; Measurements at every $90( \pm 30)$ days until 3 years from the start of the treatment. Every $180( \pm 60)$ days thereafter. 2 ; Measurements at every $180( \pm 60)$ days until 3 years from the start of the treatment. Every $365( \pm 90)$ days thereafter. *3: Measurements at $365( \pm 60)$ days and 545( \pm 60$)$ days. CT Computed tomography, MRI Magnetic resonance imaging, RI Radio isotope, PET Positron emission tomography, WPAI Work productivity and activity impairment questionnaire 
Table 1 Main Inclusion and Exclusion Criteria

\begin{tabular}{|c|}
\hline Inclusion Criteria \\
\hline 1) Patients providing the written informed consent \\
\hline $\begin{array}{l}\text { 2) Patients with non-small-cell lung cancer histopathologically } \\
\text { confirmed }\end{array}$ \\
\hline $\begin{array}{l}\text { 3) Patients with total resection in pathological clinical stage II - IIIA with } \\
\text { more than one lobe excision was carried out }\end{array}$ \\
\hline $\begin{array}{l}\text { 4) Patients with lymphadenectomy more than ND2a-1 or selective } \\
\text { lymphadenectomy }\end{array}$ \\
\hline $\begin{array}{l}\text { The selection method of the mediastinal lymph node dissected obeys } \\
\text { the following criteria }\end{array}$ \\
\hline - Right upper lobe lung cancer (LC); No.2R,4R \\
\hline - Left upper lobe segmentum superius LC; No. 4 L-6 \\
\hline -Right middle lobe LC; \\
\hline - Left upper lobe lingual LC; No.4 L-7 \\
\hline$\bullet$ Right lower lobe LC; No.7-9 \\
\hline -Left lower lobe LC; No.7-9 \\
\hline $\begin{array}{l}\text { 5) Patients without pre-treatment (radiation, chemotherapy) other than } \\
\text { surgical treatment }\end{array}$ \\
\hline $\begin{array}{l}\text { 6) Patients who passed more than } 28 \text { days and less than } 56 \text { days after } \\
\text { the operation at enrollment }\end{array}$ \\
\hline $\begin{array}{l}\text { 7) Patient is at least } 20 \text { years and less than } 75 \text { years of age (at enrollment } \\
\text { date). }\end{array}$ \\
\hline 8) Patients capable of treatment with oral medicine. \\
\hline $\begin{array}{l}\text { 9) Eastern Cooperative Oncology Group (ECOG) performance status of } \\
0-1\end{array}$ \\
\hline $\begin{array}{l}\text { 10) Patients having sufficient bone marrow, liver and renal function } \\
\text { tolerable to chemotherapy }\end{array}$ \\
\hline Exclusion Criteria \\
\hline $\begin{array}{l}\text { 1) Patients with active double cancer (synchronous double cancer and } \\
\text { asynchronous double cancer within } 5 \text { years of progression-free } \\
\text { period) }\end{array}$ \\
\hline 2) Patients with anamnesis of drug-induced hypersensitivity. \\
\hline $\begin{array}{l}\text { 3) Patients with severe postoperative complications (such as } \\
\text { postoperative infection, rapture suture). }\end{array}$ \\
\hline $\begin{array}{l}\text { 4) Patients with severe complications (such as diarrhoea, intestinal } \\
\text { paralysis, ileus, uncontrollable diabetes mellitus, heart failure, kidney } \\
\text { failure, liver failure). }\end{array}$ \\
\hline $\begin{array}{l}\text { 5) Patients with interstitial pattern recognized as apparent interstitial } \\
\text { pneumonia in chest CT. }\end{array}$ \\
\hline 6) Patients with active infection. \\
\hline 7) Female patients pregnant or possibly pregnant (will), or nursing. \\
\hline $\begin{array}{l}\text { 8) Patients under treatment with a type of fluorinated pyrimidine } \\
\text { antineoplastic. }\end{array}$ \\
\hline 9) Patients under treatment of flucytosine. \\
\hline
\end{tabular}

progression or death (whichever occurs first) or the date of last contact. Overall survival was defined as the time from the date of the start of treatment to the date of death or last contact. The Kaplan-Meier method will be used to estimate the time-to-event functions of relapsefree survival and overall survival. The log-rank test will be conducted as a reference without setting the significance level.

\section{Discussion}

Since 2004, cisplatin with vinorelbine has been the preferred treatment for patients who have undergone complete resection of stage II to IIIA NSCLC and the recommended regimen has not been changed in more than 16 years. Because the adverse reactions are severe in the cisplatin with vinorelbine regime, the Lung Cancer Group in Kyusyu (LOGIK) is conducting the LOGIK1702 study in order to compare the efficacy of milder chemotherapy using S-1 compared to the standard regimen of cisplatin with vinorelbine. S-1 chemotherapy has been successfully used for other cancers and is recommended for intestinal adjuvant chemotherapy. In previous studies using cisplatin doublet based adjuvant chemotherapies most of the relapses occurred within 2-years following the operation and the survival curve came to a plateau thereafter $[1-3,15]$. In order to estimate the efficacy of the two regimens, the primary endpoint of this study is also configured as 2-year RFS. The other aspect of this study is to evaluate work productivity and activity, and quality of adjusted life years (QALY) by using the questionnaire of the EQ-5D-5L, which was configured as a secondary endpoint. The EQ5D-5L measures five aspects of the patient's life: mobility, self-care, usual activities, pain/discomfort and anxiety/depression. Accordingly, the patients' QALY will be expressed numerically and evaluated objectively. Since better QOL and work productivity are also desired even for postoperative patients, this analysis will evaluate another aspect of the adjuvant chemotherapy in addition to prognosis. Quality of life is important as well as the longevity prognosis. To the best of our knowledge, this is the first prospective study which evaluates the QALY and work productivity in postoperative adjuvant chemotherapy.

The limitation of the present study is that this randomized study is not aimed at evaluating statistical comparison of the difference in prognoses between the two arms. Rather, this study is aimed at providing basic information for improving the performance evaluation of a future randomized phase III study. The LOGIK1702 study will give us new information on the optimal chemotherapy regimen for completely resected NSCLC.

\section{Abbreviations}

NSCLC: Non-small cell lung cancer; QOL: Quality of life; RFS: Relapse free survival; OS: Overall survival; QALY: Quality of adjusted life years;

CDDP: Cisplatin; VNR: Vinorelbine; AST: Aspartate aminotransferase; CDHP: $5-$ chloro-2,4-dihydroxypyridine; Oxo: Potassium oxonate; EQ-5D-5L: Euro QoL 5 dimensions; WPAI: Work productivity and activity impairment 


\section{Acknowledgements}

We thank the Kyushu Clinical Research Support Center for their work regarding the clinical trial and preparation of the manuscript. We also thank Dr. Mary Durbin for critical reading of the manuscript. This study is financially supported by Taiho Pharmaceutical Co., Ltd.

\section{Protocol version}

Version 2. Approved February 5, 2020

\section{Unique trial ID number \\ UMIN000027435.}

\section{Trial registration date}

May 22, 2017

\section{Authors' contributions}

$\Pi$, and TN are conducting the LOGIK1702 study as described in the protocol and drafted this manuscript. TN is the principal investigator of the study. KM, $T M, R D, H Y, K T$ and HW are contributing the recruitment of participants and data collection and critically reviewed the manuscript. ST and KS participated in the trial design and planning of the statistical analyses. All authors have read and approved the manuscript.

\section{Funding}

This study is supported by Taiho Pharmaceutical Co., Ltd. The role of the funder is for financial support for the management office only.

\section{Availability of data and materials}

Only the statistician who designed this trial will have access to the personal data of participants and to the final data set. The datasets used and/or analysed during the current study will be available from the corresponding author on reasonable request.

\section{Declarations}

\section{Ethics approval and consent to participate}

This study was conducted in accordance with the principles expressed in the Declaration of Helsinki. The primary protocol of this study was approved by the central ethics committee of Clinical Research Network Fukuoka Certified Review Board (CRB7180004) on May 2, 2017. Protocol amendments have been made in the study period and the participating institutions. The latest version (version 2) of the study protocol has been reviewed and approved by the Clinical Research Network Fukuoka Certified Review Board on February 5, 2020 (jRCTs071180010). Written informed consent will be obtained from all the participants.

\section{Consent for publication}

Not applicable.

\section{Competing interests}

The authors declare no conflicts of interest associated with this manuscript.

\section{Author details}

'Department of Surgical Oncology, Nagasaki University Graduate School of Biomedical Sciences, 1-7-1 Sakamoto, Nagasaki City 852-8501, Japan. ${ }^{2}$ Medical Information Center, Kyushu University Hospital, Kyushu, Japan. ${ }^{3}$ Second department of Internal medicine, Nagasaki University Hospital, Nagasaki, Japan. ${ }^{4}$ Department of Thoracic and Breast Surgery, Oita University, Oita, Japan.

Received: 22 May 2020 Accepted: 21 February 2021

Published online: 08 March 2021

\section{References}

1. Arriagada R, Dunant A, Pignon JP, Bergman B, Chabowski M, Grunenwald D, et al. Long-term results of the international adjuvant lung cancer trial evaluating adjuvant cisplatin-based chemotherapy in resected lung cancer. J Clin Oncol. 2010;28:35-42.

2. Dunant A, Pignon J-P, Le Chevalier T. Adjuvant chemotherapy for non-small cell lung cancer: contribution of the International Adjuvant Lung Trial. Clin Cancer Res. 2005;11:5017s-21s.
3. Winton T, Livingston R, Johnson D, Rigas J, Johnston M, Butts C, et al. Vinorelbine plus cisplatin vs. observation in resected non-small-cell lung cancer. N Engl J Med. 2005;352:2589-97.

4. Bai R, Li L, Chen X, Chen N, Song W, Cui J. Neoadjuvant and adjuvant immunotherapy: opening new horizons for patients with early-stage nonsmall cell lung Cancer. Front Oncol. 2020;10:1-10.

5. Shirasaka T, Shimamato $Y$, Ohshimo H, Yamaguchi M, Kato T, Yonekura KFM. Development of a novel form of an oral 5-fluorouracil derivative (S-1) directed to the potentiation of the tumor selective cytotoxicity of 5-fluorouracil by two biochemical modulators. Anti-Cancer Drugs. 1996; 7:548-57.

6. Maeda A, Boku N, Fukutomi A, Kondo S, Kinoshita T, Nagino M, et al. Randomized phase III trial of adjuvant chemotherapy with gemcitabine versus S-1 in patients with resected pancreatic cancer: Japan adjuvant study Group of Pancreatic Cancer (JASPAC-01). Jpn J Clin Oncol. 2008:38:227-9.

7. Sasako M, Sakuramoto S, Katai H, Kinoshita T, Furukawa H, Yamaguchi T, et al. Five-year outcomes of a randomized phase III trial comparing adjuvant chemotherapy with S-1 versus surgery alone in stage II or III gastric cancer. J Clin Oncol. 2011;29:4387-93.

8. Yoshida M, Ishiguro M, Ikejiri K, Mochizuki I, Nakamoto Y, Kinugasa Y, et al. S-1 as adjuvant chemotherapy for stage III colon cancer: a randomized phase III study (ACTS-CC trial). Ann Oncol. 2014:25:1743-9.

9. Akutsu Y, Kono T, Uesato M, Hoshino I, Narushima K, Hanaoka T, et al. S-1 monotherapy as second- or third-line chemotherapy for unresectable and recurrent esophageal squamous cell carcinoma. Oncol. 2013;84:305-10.

10. Tsukahara K, Kubota A, Hasegawa Y, Takemura H, Terada T, Taguchi T, et al. Randomized phase III trial of adjuvant chemotherapy with S-1 after curative treatment in patients with squamous-cell carcinoma of the head and neck (ACTS-HNC). PLoS One. 2015;10:1-15.

11. Teramoto $Y$, Nakamura $Y$, Yamada $K$, Yamamoto A. Oral S-1 in advanced cutaneous squamous cell carcinoma. J Dermatol. 2014:41:494-7.

12. Tsuchiya T, Nagayasu T, Yamasaki N, Matsumoto K, Miyazaki T, Tagawa T, et al. A multicenter phase II study of adjuvant chemotherapy with oral fluoropyrimidine S-1 for non-small-cell lung cancer: high completion and survival rates. Clin Lung Cancer. 2012;13:464-9.

13. Yano T, Yamazaki K, Maruyama R, Tokunaga S, Shoji F, Higashi H, et al. Feasibility study of postoperative adjuvant chemotherapy with S-1 (tegaful, gimeracil, oteracil potassium) for non-small cell lung cancer-LOGIK 0601 study. Lung Cancer. 2010;67:184-7.

14. Douillard J-Y, Tribodet H, Aubert D, Shepherd FA, Rosell R, Ding K, et al. Adjuvant Cisplatin and Vinorelbine for completely resected non-small cell lung Cancer: subgroup analysis of the lung adjuvant Cisplatin evaluation. J Thorac Oncol. 2010;5:220-8.

15. Iwamoto Y, Mitsudomi T, Sakai K, Yamanaka T, Yoshioka H, Takahama M, et al. Randomized Phase II Study of Adjuvant Chemotherapy with Longterm S-1 versus Cisplatin+S-1 in Completely Resected Stage II-IIIA Non-Small Cell Lung Cancer. Clin Cancer Res. 2015;21:5245-52.

16. Devlin NJ, Shah KK, Feng Y, Mulhern B, van Hout B. Valuing health-related quality of life: An EQ-5D-5L value set for England. Heal Econ (United Kingdom). 2018;27:7-22

\section{Publisher's Note}

Springer Nature remains neutral with regard to jurisdictional claims in published maps and institutional affiliations.

Ready to submit your research? Choose BMC and benefit from:

- fast, convenient online submission

- thorough peer review by experienced researchers in your field

- rapid publication on acceptance

- support for research data, including large and complex data types

- gold Open Access which fosters wider collaboration and increased citations

- maximum visibility for your research: over $100 \mathrm{M}$ website views per year

At BMC, research is always in progress.

Learn more biomedcentral.com/submission 